\title{
Patterns of distant metastasis in Chinese women according to breast cancer subtypes
}

\author{
San-Gang Wu1,*, Jia-Yuan Sun ${ }^{2, *}$, Li-Chao Yang ${ }^{3, *}$, Li-Ying Tang ${ }^{4}$, Xue Wang ${ }^{4}$ Xue- \\ Ting Chen ${ }^{4}$, Gui-Hua Liu ${ }^{5}$, Huan-Xin Lin ${ }^{2}$, Qin Lin ${ }^{1}$, Zhen-Yu He ${ }^{2}$ \\ ${ }^{1}$ Department of Radiation Oncology, The First Affiliated Hospital of Xiamen University, Xiamen 361003, People's Republic of \\ China \\ ${ }^{2}$ Sun Yat-sen University Cancer Center, State Key Laboratory of Oncology in South China, Department of Radiation Oncology, \\ Collaborative Innovation Center of Cancer Medicine, Guangzhou 510060, People's Republic of China \\ ${ }^{3}$ Department of Basic Medical Science, Medical College, Xiamen University, Xiamen 361005, People's Republic of China \\ ${ }^{4}$ Eye Institute of Xiamen University, Fujian Provincial Key Laboratory of Ophthalmology and Visual Science, Medical College, \\ Xiamen University, Xiamen 361005, People's Republic of China \\ ${ }^{5}$ School of Pharmaceutical Sciences, Xiamen University, Xiamen 361005, People's Republic of China \\ *These authors have contributed equally to this work \\ Correspondence to: Qin Lin, email: linqin05@163.com \\ Zhen-Yu He, email: hezhy@sysucc.org.cn \\ Keywords: breast cancer, breast cancer subtype, distant metastasis, patterns
}

Received: December 25, $2015 \quad$ Accepted: May 20, $2016 \quad$ Published: June 16, 2016

\section{ABSTRACT}

To access possible relationships between breast cancer subtypes (BCS) and patterns of distant metastasis in advanced breast cancer. Breast cancer patients with distant metastasis at two academic centers from 2000-2015 were retrospectively reviewed. The breast cancer was classified into four subtypes: hormone receptor (HR) + / human epidermal growth factor receptor 2 (HER2) - (i.e., estrogen receptor [ER] + and/or progesterone receptor [PR] +, HER2-); HR+/HER2+ (ER+ and/or PR+, HER2+), HR-/HER2+ (ER- and PR-, and HER2+); and HR-/HER2- (ERand PR-, and HER2-). A total of 679 patients were identified. The distribution of the BCS was $39.9 \%(271 / 679), 23.7 \%(161 / 679), 16.8 \%(114 / 679)$, and $19.6 \%$ (133/679) in HR+/HER2-, HR+/HER2+, HR-/HER2+, and HR-/HER2-, respectively. Patients with HR+/HER2+ and HR-/HER2+ subtypes were prone to abdominal and pelvic metastasis, those with HR+/HER2- and HR+/HER2+ subtypes were prone to bone metastasis, while patients with the HR-/HER2- subtype were prone to lung/ mediastinal and brain metastases. In patients with pleural, axillary and/or neck lymph node, and other distant soft tissue metastases, there was no significant difference in metastatic patterns among the BCS. There are different patterns of distant metastasis associated with different BCS. There should be a different focus in the postoperative follow-up and monitoring of breast cancer patients with different BCS.

\section{INTRODUCTION}

Breast cancer is the most common malignancy in women worldwide. It is estimated that there will be about 232,000 new cases of breast cancer diagnosed in the United States in 2015 [1]. In China, there is also a rapid growth trend in breast cancer, and cancer prevalence estimates for 5 years are 1.02 million women with breast cancer [2]. Although great progress has been made in the comprehensive treatment of breast cancer, $20 \%-30 \%$ of patients will still develop distant metastases [3-5]. Bone, lung, liver, and brain are the most common metastatic sites of breast cancer [6], but there is a difference in the survival of patients for different metastatic sites [7,8].

Currently, common risk factors for distant metastasis of breast cancer include tumor size, nodal stage, histological grade, estrogen receptor (ER), progesterone receptor (PR), human epidermal growth factor receptor 
2 (HER2), and others [9-11]. Traditional tumor-nodemetastasis (TNM)-staging may predict the risk of breast cancer metastasis and death, but the predictive value for specific sites of metastasis is poor. Breast cancer, a heterogeneous disease composed of distinct biological subtypes, can be divided into four simple subtypes based on ER, PR and HER2 status: hormone receptor (HR)+/HER2-, HR+/HER2+, HR-/HER+, and HR-/ HER2- [12-14]. The breast cancer subtypes (BCS) are increasingly recognized as predictive factors for disease control and response to adjuvant therapies including chemotherapy, radiotherapy and targeted therapy [1517]. However, data are limited and conflict concerning differences in specific sites of distant metastasis among the various BCS [18-21]. In this study, we sought to access the possible relationships between BCS and patterns of distant metastasis in advanced breast cancer patients from two cancer centers to aid in the development of personalized programs of surveillance.

\section{RESULTS}

\section{Patient characteristics}

Six hundred and seventy-nine patients were identified, 493 (72.6\%) from Sun Yat-sen University Cancer Center (SYSUCC) and 186 (27.4\%) from the First Affiliated Hospital of Xiamen University (Xiamen Cancer Center, XMCC). Table 1 shows clinicopathological data of the patients. The median age was 46.8 years (range 2387 ) when breast cancer was diagnosed, $64.5 \%$ (438/679) of patients were premenopausal. Five hundred and twentynine patients (77.9\%) were in Tumor (T)1-T2 stage, and 371 patients $(54.6 \%)$ were in Node $(\mathrm{N}) 2-\mathrm{N} 3$ stage. In patients with distant metastasis, HR+/HER2-, HR+/HER2+, HR-/ HER2+ and HR-/HER2- BCS accounted for $39.9 \%$ (271/679), 23.7\% (161/679), 16.8\% (114/679), and 19.6\% $(133 / 679)$, respectively. Nodal stage was significantly different among the four BCS $(\mathrm{P}=0.045)$ (Table 2). No significant differences in age, menopausal status, tumor size, and histotype were found among the four BCSs.

\section{Distant metastasis of patients}

The median follow-up period among patients diagnosed with metastatic breast cancer was 26.7 months. The 1-year, 2-year, and 3-year overall survival (OS) was $74.3 \%, 49.3 \%$ and $34.5 \%$, respectively. The median distant metastasis time of HR+/HER2-, HR+/HER2+, HR-/HER 2 + and HR-/HER2- was $41.0 \pm 26.9$ months, $32.3 \pm 27.6$ months, $22.8 \pm 15.8$ months and $26.9 \pm 20.6$ months, respectively $(\mathrm{P}<0.001)$. Of the 679 patients, there were 1025 sites of distant metastases were definitely identified (Figure 1); 445 patients had a solitary metastasis and 234 patients had multiple metastases. Common sites of metastasis included bone $(30.0 \%, 308 / 1025)$, lung/ mediastinum (24.2\%, 248/1025), abdomen/pelvis (21.6\%, $221 / 1025)$, brain $(7.6 \%, 78 / 1025)$, axillary and/or neck lymph nodes $(6.7 \%, 69 / 1025)$, pleura $(6.0 \%, 62 / 1025)$, and other distant soft tissue $(3.8 \%, 39 / 1025)$. There was no significant correlation between BCS and the number of distant organ metastases $(P=0.674)$. Univariate and multivariate analysis showed that nodal stage was a risk factor affecting lung/mediastinal, and axillary and/or neck lymph node metastasis $(\mathrm{P}<0.05)$, while histotype was a risk factor affecting pleural metastasis $(\mathrm{P}<0.05)$. Age, menopausal status, tumor size and Ki-67 level did not affect the patterns of distant metastasis.

\section{Association of breast cancer subtypes with the sites of distant relapse}

Univariate and multivariate analysis showed that HR+/HER2+ and HR-/HER2+ subtype patients had a higher probability of abdominal/pelvic metastasis compared to HR+/HER2 - subtype patients, while the probability of abdominal/pelvic metastasis of the HR-/ HER2+ subtype was higher than that of the HR-/HER2subtype. Multivariate analysis showed that the probability of abdominal/pelvic metastasis of the HR+/HER2+ subtype was also higher than that of the HR-/HER2subtype (Table 3; Figure 2).

Univariate and multivariate analysis showed that HR-/HER2 - had a significantly higher probability of lung/mediastinal metastasis than the other three subtypes. There were no significant differences in the probability of lung/mediastinal metastases among the other three subtypes (Table 3; Figure 2).

In terms of bone metastases, univariate and multivariate analysis showed that the probability of bone metastasis of HR+/HER2- and HR+/HER2+ subtypes was significantly higher than that of the HR-/HER2+ and HR-/HER2 - subtypes, while there was no significant difference in the probability of bone metastasis between HR+/HER2 - and HR+/HER2+ (Table 3; Figure 2).

The probability of brain metastasis of HR-/HER2was significantly higher than that of the HR+/HER2subtype, but there were no significant differences in brain metastasis among the other subtypes (Table 3; Figure 2).

\section{DISCUSSION}

In this study, we investigated the relationships between BCS and distant metastasis sites of breast cancer. The various BCSs had site-specific metastasis patterns, patients with HR+/HER2+ and HR-/HER2+ subtypes were prone to abdominal/pelvic metastasis, patients with $\mathrm{HR}+/ \mathrm{HER} 2-$ and HR+/HER2+ subtypes were prone to bone metastasis, while patients with the HR-/ HER2 - subtype were prone to lung/mediastinal and brain metastases. 
Table 1: Summary of characteristics in 679 patients enrolled in this study

\begin{tabular}{|c|c|c|c|}
\hline Characteristic & $\mathbf{n}$ & SYSUCC & XMCC \\
\hline Age (median, years) & $46.8 \pm 10.8$ & $46.1 \pm 10.7$ & $48.5 \pm 10.9$ \\
\hline \multicolumn{4}{|l|}{ Menopausal status } \\
\hline Premenopausal & 438 & 322 & 116 \\
\hline Postmenopausal & 241 & 171 & 70 \\
\hline \multicolumn{4}{|l|}{ Tumor size } \\
\hline $\mathrm{T} 1$ & 161 & 115 & 46 \\
\hline $\mathrm{T} 2$ & 368 & 264 & 104 \\
\hline $\mathrm{T} 3$ & 105 & 76 & 29 \\
\hline $\mathrm{T} 4$ & 45 & 38 & 7 \\
\hline \multicolumn{4}{|l|}{ Nodal stage } \\
\hline No & 171 & 130 & 41 \\
\hline N1 & 137 & 93 & 44 \\
\hline N2 & 167 & 122 & 45 \\
\hline N3 & 204 & 148 & 56 \\
\hline \multicolumn{4}{|l|}{ Histotype } \\
\hline Invasive ductal carcinoma & 638 & 471 & 167 \\
\hline Other & 41 & 22 & 19 \\
\hline \multicolumn{4}{|l|}{$\mathrm{Ki}-67(\mathrm{n}=310)$} \\
\hline$\leq 25 \%$ positive & 152 & 130 & 22 \\
\hline$>25 \%$ positive & 158 & 89 & 69 \\
\hline \multicolumn{4}{|l|}{ Breast cancer subtype } \\
\hline HR+/HER2- & 271 & 193 & 78 \\
\hline HR+/HER2+ & 161 & 111 & 50 \\
\hline HR-/HER2+ & 114 & 91 & 23 \\
\hline HR-/HER2- & 133 & 98 & 35 \\
\hline \multicolumn{4}{|l|}{ Site of distant metastasis $(\mathrm{n}=1025)$} \\
\hline Abdomen/pelvis & 221 & 172 & 49 \\
\hline Lung/mediastinum & 248 & 179 & 69 \\
\hline Pleura & 62 & 34 & 28 \\
\hline Bone & 308 & 201 & 107 \\
\hline Axillary and/or neck lymph nodes & 69 & 42 & 27 \\
\hline Brain & 78 & 47 & 31 \\
\hline Other distant soft tissue & 39 & 24 & 15 \\
\hline
\end{tabular}

SYSUCC, Sun Yat-sen University Cancer Center; XMCC, Xiamen Cancer Center; T, tumor; N, node; HR, hormone receptor; HER2, human epidermal growth factor receptor 2. 
Table 2: Clinicopathological characteristics according to breast cancer subtype

\begin{tabular}{|c|c|c|c|c|c|}
\hline Characteristic & HR+/HER2- & HR+/HER2+ & HR-/HER2+ & HR-/HER2- & Pvalue \\
\hline Age (median, years) & $46.6 \pm 11.3$ & $46.0 \pm 10.9$ & $48.4 \pm 10.7$ & $46.8 \pm 9.7$ & 0.345 \\
\hline \multicolumn{6}{|l|}{ Menopausal status } \\
\hline Premenopausal & 181 & 109 & 62 & 86 & \multirow[t]{2}{*}{0.092} \\
\hline Postmenopausal & 90 & 52 & 52 & 47 & \\
\hline \multicolumn{6}{|l|}{ Tumor size } \\
\hline $\mathrm{T} 1$ & 66 & 31 & 28 & 36 & \multirow[t]{4}{*}{0.058} \\
\hline $\mathrm{T} 2$ & 152 & 88 & 61 & 67 & \\
\hline $\mathrm{T} 3$ & 28 & 35 & 19 & 23 & \\
\hline $\mathrm{T} 4$ & 25 & 7 & 6 & 7 & \\
\hline \multicolumn{6}{|l|}{ Nodal stage } \\
\hline No & 66 & 36 & 25 & 44 & \multirow[t]{4}{*}{0.045} \\
\hline N1 & 67 & 26 & 19 & 25 & \\
\hline $\mathrm{N} 2$ & 69 & 39 & 34 & 25 & \\
\hline N3 & 69 & 60 & 36 & 39 & \\
\hline \multicolumn{6}{|l|}{ Histotype } \\
\hline Invasive ductal carcinoma & 251 & 151 & 111 & 125 & \multirow[t]{2}{*}{0.355} \\
\hline Other & 20 & 10 & 3 & 8 & \\
\hline
\end{tabular}

T, tumor; N, node; HR, hormone receptor; HER2, human epidermal growth factor receptor 2.

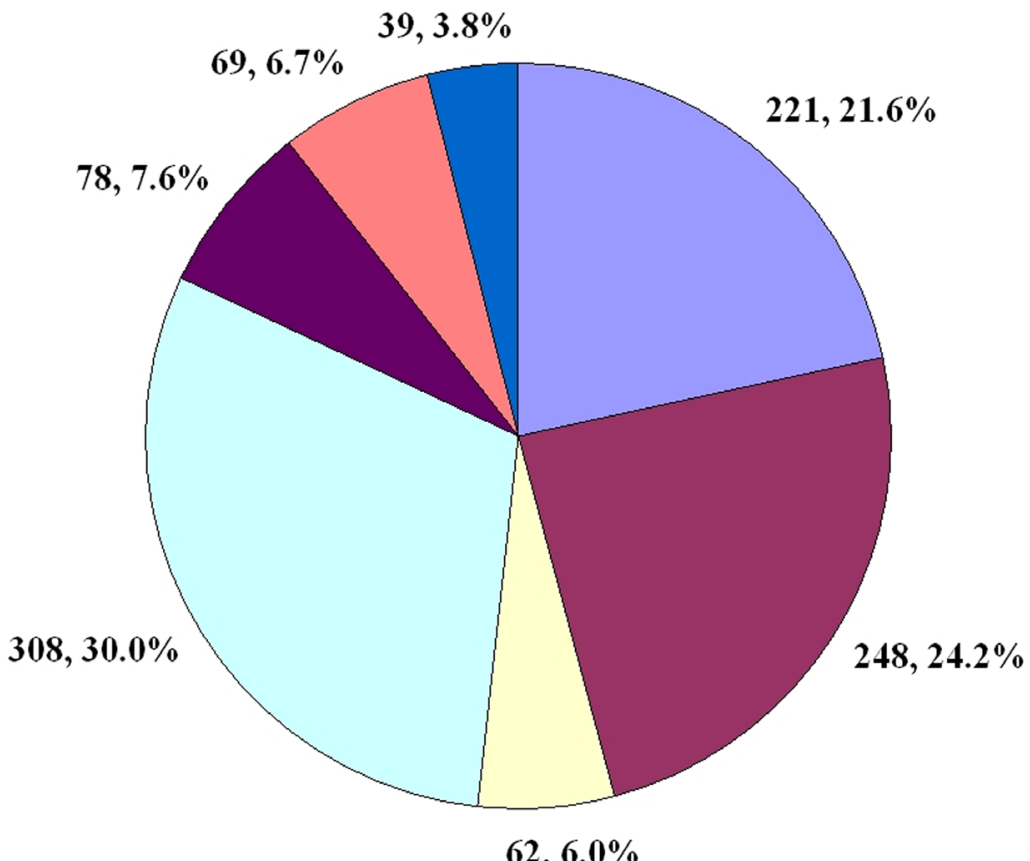

\begin{tabular}{|l|}
\hline Abdomen/pelvis \\
$\square$ Lung/mediastinal \\
$\square$ Pleura \\
$\square$ Bone \\
$\square$ Brain \\
$\square$ Axillary and/or neck lymph nodes \\
$\square$ Other distant soft tissue \\
\hline
\end{tabular}

Figure 1: The frequencies of the sites of distant metastasis. 
Table 3: Specific breast cancer subtypes associated with the sites of distant metastasis

\begin{tabular}{|c|c|c|c|c|c|c|}
\hline \multirow[t]{2}{*}{$\begin{array}{l}\text { Site of distant } \\
\text { metastasis/subtype }\end{array}$} & \multicolumn{3}{|c|}{ Univariate } & \multicolumn{3}{|c|}{ Multivariate } \\
\hline & OR & $95 \%$ CI & Pvalue & OR & $95 \% \mathrm{CI}$ & Pvalue \\
\hline \multicolumn{7}{|l|}{ Abdomen/pelvis } \\
\hline HR+/HER 2+ vs. HR+/HER2- & 1.594 & $1.053-2.414$ & $0.028^{*}$ & 1.665 & $1.096-2.530$ & $0.017^{*}$ \\
\hline HR-/HER2+ vs. HR+/HER2- & 1.901 & $1.203-3.002$ & $0.006^{*}$ & 1.971 & $1.244-3.124$ & $0.004 *$ \\
\hline HR-/HER2- vs. HR+/HER2- & 1.007 & $0.634-1.601$ & 0.976 & 0.933 & $0.624-1.581$ & 0.977 \\
\hline HR-/HER2+ vs. HR+/HER2+ & 1.192 & $0.731-1.945$ & 0.481 & 1.184 & $0.724-1.936$ & 0.501 \\
\hline HR-/HER2- vs. HR+/HER2+ & 0.632 & $0.385-1.037$ & 0.069 & 0.596 & $0.662-0.984$ & $0.043^{*}$ \\
\hline HR-/HER2+ vs. HR-/HER2- & 1.887 & $1.109-3.209$ & $0.019^{*}$ & 1.964 & $1.147-3.361$ & $0.014^{*}$ \\
\hline \multicolumn{7}{|l|}{ Lung/mediastinum } \\
\hline HR+/HER 2+ vs. HR+/HER2- & 1.092 & $0.720-1.659$ & 0.678 & 1.138 & $0.747-1.733$ & 0.548 \\
\hline HR-/HER2+ vs. HR+/HER2- & 1.113 & $0.698-1.775$ & 0.653 & 1.150 & $0.719-1.838$ & 0.560 \\
\hline HR-/HER2- vs. HR+/HER2- & 2.709 & $1.766-4.154$ & $<0.001^{*}$ & 2.697 & $1.755-4145$ & $<0.001 *$ \\
\hline HR-/HER2+ vs. HR+/HER2+ & 1.019 & $0.612-1.696$ & 0.943 & 1.010 & $0.606-1.686$ & 0.968 \\
\hline HR-/HER2- vs. HR+/HER2+ & 2.479 & $1.543-3.983$ & $<0.001^{*}$ & 2.370 & $1.471-3.820$ & $<0.001^{*}$ \\
\hline HR-/HER2+ vs. HR-/HER2- & 0.411 & $0.245-0.690$ & $0.001 *$ & 0.425 & $0.252-0.717$ & $0.001 *$ \\
\hline \multicolumn{7}{|l|}{ Pleura } \\
\hline HR+/HER2+ vs. HR+/HER2- & 0.997 & $0.520-1.913$ & 0.993 & 1.029 & $0.533-1.987$ & 0.932 \\
\hline HR-/HER2+ vs. HR+/HER2- & 0.502 & $0.201-1.251$ & 0.139 & 0.552 & $0.220-1.387$ & 0.206 \\
\hline HR-/HER2- vs. HR+/HER2- & 0.979 & $0.488-1.965$ & 0.952 & 0.991 & $0.491-2.000$ & 0.981 \\
\hline HR-/HER2+ vs. HR+/HER2+ & 0.503 & $0.191-1.329$ & 0.166 & 0.537 & $0.201-1.429$ & 0.213 \\
\hline HR-/HER2- vs. HR+/HER2+ & 0.982 & $0.454-2.122$ & 0.963 & 0.963 & $0.442-2.101$ & 0.925 \\
\hline HR-/HER2+ vs. HR-/HER2- & 0.513 & $0.188-1.396$ & 0.191 & 0.557 & $0.203-1.527$ & 0.256 \\
\hline \multicolumn{7}{|l|}{ Bone } \\
\hline HR+/HER2+ vs. HR+/HER2- & 0.809 & $0.547-1.195$ & 0.287 & 0.809 & $0.547-1.195$ & 0.287 \\
\hline HR-/HER2+ vs. HR+/HER2- & 0.426 & $0.270-0.671$ & $<0.001^{*}$ & 0.426 & $0.270-0.671$ & $<0.001^{*}$ \\
\hline HR-/HER2- vs. HR+/HER2- & 0.352 & $0.227-0.547$ & $<0.001^{*}$ & 0.352 & $0.227-0.547$ & $<0.001^{*}$ \\
\hline HR-/HER $2+$ vs. HR+/HER2+ & 0.527 & $0.321-0.864$ & $0.011^{*}$ & 0.527 & $0.321-0.864$ & $0.011^{*}$ \\
\hline HR-/HER2- vs. HR+/HER2+ & 0.435 & $0.269-0.706$ & $0.001 *$ & 0.435 & $0.269-0.706$ & $0.001 *$ \\
\hline HR-/HER2+ vs. HR-/HER2- & 1.209 & $0.708-2.066$ & 0.487 & 1.251 & $0.729-2.147$ & 0.417 \\
\hline \multicolumn{7}{|l|}{ Brain } \\
\hline HR+/HER2+ vs. HR+/HER2- & 1.443 & $0.759-2.741$ & 0.263 & 1.462 & $0.768-2.783$ & 0.248 \\
\hline HR-/HER2+ vs. HR+/HER2- & 1.634 & $0.819-3.260$ & 0.164 & 1.690 & $0.843-3.388$ & 0.140 \\
\hline HR-/HER2- vs. HR+/HER2- & 2.022 & $1.074-3.805$ & $0.029 *$ & 2.054 & $1.089-3.874$ & $0.026^{*}$ \\
\hline HR-/HER2+ vs. HR+/HER2+ & 1.132 & $0.549-2.336$ & 0.736 & 1.156 & $0.558-2.396$ & 0.697 \\
\hline HR-/HER2- vs. HR+/HER2+ & 1.401 & $0.718-2.734$ & 0.322 & 1.405 & $0.719-2.747$ & 0.320 \\
\hline HR-/HER2+ vs. HR-/HER2- & 0.808 & $0.395-1.653$ & 0.559 & 0.833 & $0.404-1.717$ & 0.620 \\
\hline
\end{tabular}

(Continued) 


\begin{tabular}{|c|c|c|c|c|c|c|}
\hline \multirow{2}{*}{$\begin{array}{l}\text { Site of distant } \\
\text { metastasis/subtype }\end{array}$} & \multicolumn{3}{|c|}{ Univariate } & \multicolumn{3}{|c|}{ Multivariate } \\
\hline & OR & $95 \% \mathrm{CI}$ & Pvalue & OR & $95 \% \mathrm{CI}$ & Pvalue \\
\hline \multicolumn{7}{|l|}{$\begin{array}{l}\text { Axillary and/or neck lymph } \\
\text { nodes }\end{array}$} \\
\hline HR+/HER2+ vs. HR+/HER2- & 1.698 & $0.902-3.197$ & 0.101 & 1.588 & $0.836-3.016$ & 0.158 \\
\hline HR-/HER2+ vs. HR+/HER2- & 1.457 & $0.707-3.004$ & 0.308 & 1.420 & $0.680-2.963$ & 0.350 \\
\hline HR-/HER2- vs. HR+/HER2- & 1.226 & $0.597-2.518$ & 0.579 & 1.262 & $0.611-2.608$ & 0.529 \\
\hline HR-/HER2+ vs. HR+/HER2+ & 0.858 & $0.410-1.794$ & 0.684 & 0.894 & $0.422-1.892$ & 0.770 \\
\hline HR-/HER2- vs. HR+/HER2+ & 0.722 & $0.347-1.504$ & 0.384 & 0.795 & $0.378-1.671$ & 0.545 \\
\hline HR-/HER2+ vs. HR-/HER2- & 1.188 & $0.527-2.679$ & 0.678 & 1.128 & $0.495-2.567$ & 0.775 \\
\hline \multicolumn{7}{|l|}{ Other distant soft tissue } \\
\hline HR+/HER2+ vs. HR+/HER2- & 1.455 & $0.636-3.330$ & 0.374 & 1.410 & $0.613-3.242$ & 0.419 \\
\hline HR-/HER2+ vs. HR+/HER2- & 0.910 & $0.317-2.616$ & 0.862 & 0.921 & $0.318-2.665$ & 0.880 \\
\hline HR-/HER2- vs. HR+/HER2- & 1.614 & $0.688-3.782$ & 0.271 & 1.664 & $0.707-3.915$ & 0.243 \\
\hline HR-/HER2+ vs. HR+/HER2+ & 0.626 & $0.211-1.852$ & 0.397 & 0.654 & $0.220-1.942$ & 0.444 \\
\hline HR-/HER2- vs. HR+/HER2+ & 1.109 & $0.456-2.697$ & 0.820 & 1.181 & $0.482-2.891$ & 0.716 \\
\hline HR-/HER2+ vs. HR-/HER2- & 0.564 & $0.187-1.702$ & 0.310 & 0.564 & $0.186-1.712$ & 0.312 \\
\hline
\end{tabular}

* Indicates a significant difference at $\mathrm{P}<0.05$.

HR, hormone receptor; HER2, human epidermal growth factor receptor 2; OR, odds ratio; CI, confidence interval.

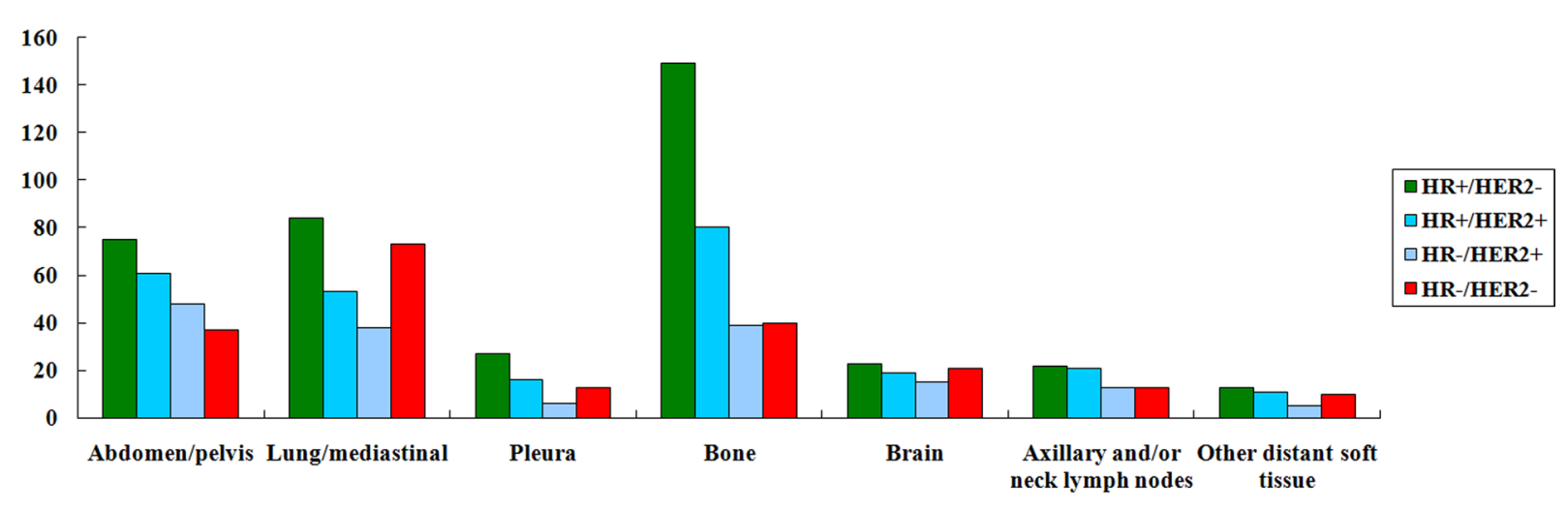

Figure 2: The frequencies of the sites of distant metastasis by breast cancer subtypes.

Breast cancer subtype is an important factor affecting the survival of breast cancer patients irrespective of distant metastasis. In general, the survival of HR+ patients is superior to that of HER2+ and HR-/HER2(also called triple-negative breast cancer [TNBC]) patients [15-17]. Park et al. found that BCS did not affect the OS of patients with early recurrence (distant metastases within 24 months after surgery; $\mathrm{P}=0.08)$, but for patients with distant metastases $\geq 24$ months after surgery, BCS significantly affected the OS, and the survival of $\mathrm{HR}+/$ HER2 - and HR-/HER2+ patients was superior to that of the HR+/HER2+ and HR-/HER2 - groups $(\mathrm{P}<0.001)$
[18]. Considering the St Gallen molecular subtypes (2013), Gerratana et al. found that the median survival time for luminal HER2+ was 56.7 months, luminal A 45.3 months, luminal B 31.1 months, non-luminal HER2+ 21.5 months, and TNBC 9.3 months $(\mathrm{P}<0.0001)$ [19]. Based on our results and related studies, BCS has both prognostic value for newly diagnosed and advanced breast cancer patients, and can also predict the patterns of distant metastases.

There may be organ-specific metastases associated with different BCSs, which supports the hypothesis that breast cancer is a systemic disease with heterogeneous 
characteristics. Bone metastasis is the most common metastasis of breast cancer, but the predictive value of BCS for bone metastasis is still controversial. Previous studies have tended to suggest that $\mathrm{HR}+$ patients are more prone to bone metastases [19, 22-24]. Our results also showed that the probability of bone metastasis in patients with HR+ subtypes (HR+/HER2 - and HR+/HER2+) was significantly higher than that for patients with $\mathrm{HR}-$ subtypes (HR-/HER2- and HR-/HER2+). However, two studies of the Korean population did not find a significant correlation between BCS and bone metastasis [18, 20]. In a study of the Chinese population, the probability of bone metastasis in patients with a HER2+ subtype was lower than in TNBC $(\mathrm{P}=0.048)$, but there was only borderline significance compared with $\mathrm{HR}+/ \mathrm{HER} 2-$ patients $(\mathrm{P}=$ $0.058)$ [25].

Our study found that breast cancer with the HER2+ subtype (HR+/HER2+ and HR-/HER2+) is more prone to abdominal and pelvic metastases than the other BCS, and most of patients with abdominal and pelvic metastases were liver metastases. The study of Kennecke et al. found that the probability of liver metastasis in patients with luminal A (ER+ and/ or $\mathrm{PR}+$ and $\mathrm{Ki}-67<14 \%)$, luminal $\mathrm{B}(\mathrm{ER}+$ and/or $\mathrm{PR}+$ and Ki-67 $\geq 14 \%$ ), HR+/HER2+, HR-/HER2+ and TNBC subtypes was 7.9\%, 13.8\%, 21.3\%, 23.3\% and $10.7 \%$, respectively [21]. The study of Park et al. did not find differences in liver metastasis between different subtypes [18], but there were only 18 patients with liver metastases in Park's study, whereas the number of patients with abdominal and pelvic metastasis in our study was 221 , and there were 435 patients with liver metastasis in the study of Kennecke et al. [21]. The large differences in sample size may be the main reason leading to different results. In our study and the research of Kennecke et al., most of the patients did not take trastuzumab treatment; therefore, it is not yet clear whether anti-HER2 therapy may affect the patterns of distant metastases. However, in the study of Olson et al., 113 HER2+ patients who received trastuzumab-based therapy diagnosed with distant metastases during the follow-up period, and $41 \%$ of these patients had liver metastases [26], suggesting that anti-HER2 therapy may not affect the patterns of distant metastases.

Because of the lack of appropriate therapeutic targets, patients with TNBC exhibit a poor prognosis due to occurred early distant metastasis [6]. Our results showed that the median distant metastasis time of TNBC was significantly earlier than $\mathrm{HR}+$ breast cancer, while the probability of lung metastasis in patients with TNBC was significantly higher than for the other three subtypes. The research of Soni et al. also found that the probability of lung metastasis of TNBC was significantly higher than that of the $\mathrm{HR}+/ \mathrm{HER} 2-$ and HR+/HER2+ subtypes, but was not different from HR-/HER2+ [27]. In advanced
TNBC, the probability of lung metastasis can reach to $40 \%$ compared with only $20 \%$ in non-TNBC [6]. There was an overexpression of epidermal growth factor receptor (EGFR) in $>50 \%$ of patients with TNBC [28, 29], and it was found from a tumor microarray study that patients with significantly elevated expression of EGFR were more prone to lung metastasis [22]. It has found that the EGFR inhibitors erlotinib could prevent development of lung metastases in a spontaneous lung metastasis breast cancer mouse model [30]. In addition, patients with high expression of EGFR were more prone to brain metastases [31], which is consistent with the high probability of brain metastases of TNBC in other studies [21, 32] as well as ours.

There are several limitations of the present study. First, there is an inherent bias that exists in any retrospective study. However, a major strength of the study is that the large number of patients with distant metastases in this cohort allowed clear demonstration of the distant metastasis patterns according to BCS. Second, the time span of the patients included is large, while the adjuvant treatment of breast cancer has made rapid progress in recent years; therefore the systemic therapy guidelines during the era of this study are not representative of current practice guidelines. But whether these will affect the patterns of breast cancer metastasis is still unclear. In addition, Ki-67 is an important marker for the molecular subtypes, but Ki-67 data was not available for $>50 \%$ of the patients in our study. Therefore, Ki-67 was not used as a marker for the BCS in our study. However, Kennecke et al. found that the distant metastasis rate in various organs in luminal $\mathrm{B}(\mathrm{ER}+$ and/or $\mathrm{PR}+$ and $\mathrm{Ki}-67 \geq 14 \%$ ) patients was higher than for luminal A (ER+ and/or PR+ and Ki-67 $<14 \%$ ) [21], indicating that $\mathrm{Ki}-67$ had a potential impact on the metastasis patterns.

In conclusion, or results showed that the BCS based on ER, PR and HER2 status have different patterns of distant metastasis. There should be a different focus in postoperative follow-up and monitoring for breast cancer patients with various BCS, and there should be further exploration of the individualized treatment for different BCS to reduce the risk of specific sites of distant metastases.

\section{MATERIALS AND METHODS}

\section{Patients}

A retrospective analysis was conducted of breast cancer patients who underwent surgery in SYSUCC and the First Affiliated Hospital of Xiamen University (Xiamen Cancer Center, XMCC) from December 2000 to April 2015. Patients in the study were met the following criteria: 1) female, unilateral invasive breast cancer without distant metastasis in the initial 
diagnosis; 2) received mastectomy or breast-conserving surgery and axillary lymph node dissection; 3 ) sites of metastases were definitely identified during follow-up; 4) complete data on the following: age, menopausal status, tumor size, nodal status, histotype, and ER, PR as well as HER2 status. We excluded patients with primary cancer before the diagnosis of breast cancer and second cancer after breast cancer. The study was approved by the Ethics Committees of the SYSUCC and XMCC.

\section{Clinicopathological factors}

Age, menstrual status, T stage, N stage, histotype and BCS were used to evaluate the patterns of distant metastasis. HR positivity was defined as $\geq 1 \%$ positive cells in ER or PR immunohistochemistry. HER2 positivity was defined as an immunohistochemical grade of 3+ (uniform and intensity membrane staining of $>30 \%$ of invasive tumor cells), or (after 2003 only) of $2+$ determined by dual-probe fluorescence in situ hybridization. The cutoff point of higher $\mathrm{Ki}-67$ expression was defined as $25 \%$ based on our previous studies [33]. Since Ki-67 data was missing for many patients, the BCS was not defined according to the St Gallen International Expert Consensus [34]. Instead, we defined four-major intrinsic BCS [11-13]: HR+/HER2- (ER+ and/or PR+, HER2-), $\mathrm{HR}+/ \mathrm{HER} 2+(\mathrm{ER}+$ and/or $\mathrm{PR}+, \mathrm{HER} 2+), \mathrm{HR}-/ \mathrm{HER} 2+$ $(\mathrm{ER}-, \mathrm{PR}-$ and HER2 +$)$ and HR-/HER2- (ER-, PR - and HER2-).

\section{Sites of distant metastasis}

The synchronous metastatic sites of breast cancer were classified into seven areas in previous study, including abdomen/pelvis (liver, adrenal gland, lymph nodes, and other abdomino-pelvic organs); lung/ mediastinum (lung or pulmonary lymphangitic spread); bone (skeletal system); pleura (pleura and/or pleural effusion and/or pericardial effusion); brain; axillary and/ or neck lymph nodes; and other distant soft tissue [35].

\section{Statistical analysis}

All data were analyzed using the SPSS statistical software package (version 21.0; IBM Corporation, Armonk, NY, USA). The $\chi^{2}$ and Fisher's exact probability tests were used to analyze the differences between qualitative data. The continuous variables were compared using Student's t-test. The association of patient characteristics factors and patterns of distant metastasis was modeled with univariate and multivariable logistic regression analysis. Predictive factors for distant metastasis were determined by multivariable logistic regression analysis, in which factors that were statistically significant in univariate analysis were entered into the multivariable logistic regression analysis. A P-value $<0.05$ was considered significant in all analyzes.

\section{ACKNOWLEDGMENTS}

This work was supported by grants from the National Natural Science Foundation of China (No. 81402527), the Sci-Tech Office of Guangdong Province (No. 2013B021800157, 2013B021800458), and the Natural Science Foundation of Fujian Province (No. 2016J01635).

\section{CONFLICTS OF INTEREST}

No any actual or potential conflicts of interest exist.

\section{REFERENCES}

1. Siegel RL, Miller KD, Jemal A. Cancer statistics, 2015. CA Cancer J Clin. 2015; 65:5-29

2. Zheng R, Zeng H, Zhang S, Chen T, Chen W. National estimates of cancer prevalence in China, 2011. Cancer Lett. 2016; 370:33-38.

3. Eckhardt BL, Francis PA, Parker BS, Anderson RL. Strategies for the discovery and development of therapies for metastatic breast cancer. Nat Rev Drug Discov. 2012; 11:479-497.

4. Kennecke $\mathrm{H}$, Yerushalmi R, Woods R, Cheang MC, Voduc D, Speers CH, Nielsen TO, Gelmon K. Metastatic behavior of breast cancer subtypes. J Clin Oncol. 2010; 28:3271-3277.

5. Redig AJ, McAllister SS. Breast cancer as a systemic disease: a view of metastasis. J Intern Med. 2013; 274:113-126.

6. Foulkes WD, Smith IE, Reis-Filho JS. Triple-negative breast cancer. N Engl J Med. 2010; 363:1938-1948.

7. Kast K, Link T, Friedrich K, Petzold A, Niedostatek A, Schoffer O, Werner C, Klug SJ, Werner A, Gatzweiler A, Richter B, Baretton G, Wimberger P. Impact of breast cancer subtypes and patterns of metastasis on outcome. Breast Cancer Res Treat. 2015; 150:621-629.

8. Bonotto M, Gerratana L, Poletto E, Driol P, Giangreco M, Russo S, Minisini AM, Andreetta C, Mansutti M, Pisa FE, Fasola G, Puglisi F. Measures of outcome in metastatic breast cancer: insights from a real-world scenario. Oncologist. 2014; 19:608-615.

9. Chia S, Norris B, Speers C, Cheang M, Gilks B, Gown AM, Huntsman D, Olivotto IA, Nielsen TO, Gelmon K. Human epidermal growth factor receptor 2 overexpression as a prognostic factor in a large tissue microarray series of nodenegative breast cancers. J Clin Oncol. 2008; 26:5697-5704. 
10. Alanko A, Heinonen E, Scheinin T, Tolppanen EM, Vihko R. Significance of estrogen and progesterone receptors, disease-free interval, and site of first metastasis on survival of breast cancer patients. Cancer. 1985; 56:1696-1700.

11. Soerjomataram I, Louwman MW, Ribot JG, Roukema JA, Coebergh JW. An overview of prognostic factors for longterm survivors of breast cancer. Breast Cancer Res Treat. 2008; 107:309-330.

12. van 't Veer LJ, Dai H, van de Vijver MJ, He YD, Hart AA, Mao M, Peterse HL, van der Kooy K, Marton MJ, Witteveen AT, Schreiber GJ, Kerkhoven RM, Roberts C, Linsley PS, Bernards R, Friend SH. Gene expression profiling predicts clinical outcome of breast cancer. Nature. 2002; 415:530-536.

13. Sorlie T, Tibshirani R, Parker J, Hastie T, Marron JS, Nobel A, Deng S, Johnsen H, Pesich R, Geisler S, Demeter J, Perou CM, Lønning PE, Brown PO, Børresen-Dale AL, Botstein D. Repeated observation of breast tumor subtypes in independent gene expression data sets. Proc Natl Acad Sci U S A. 2003; 100:8418-8423.

14. Tang P, Skinner KA, Hicks DG. Molecular classification of breast carcinomas by immunohistochemical analysis: are we ready? Diagn Mol Pathol. 2009; 18:125-132.

15. Arvold ND, Taghian AG, Niemierko A, Abi Raad RF, Sreedhara M, Nguyen PL, Bellon JR, Wong JS, Smith BL, Harris JR. Age, breast cancer subtype approximation, and local recurrence after breast-conserving therapy. J Clin Oncol. 2011; 29:3885-3891.

16. Braunstein LZ, Niemierko A, Shenouda MN, Truong L, Sadek BT, Abi Raad R, Wong JS, Punglia RS, Taghian AG, Bellon JR. Outcome following local-regional recurrence in women with early-stage breast cancer: impact of biologic subtype. Breast J. 2015; 21:161-167.

17. Wu SG, He ZY, Li Q, Li FY, Lin Q, Lin HX, Guan XX. Predictive value of breast cancer molecular subtypes in Chinese patients with four or more positive nodes after postmastectomy radiotherapy. Breast. 2012; 21:657-661.

18. Park HS, Kim S, Kim K, Yoo H, Chae BJ, Bae JS, Song BJ, Jung SS. Pattern of distant recurrence according to the molecular subtypes in Korean women with breast cancer. World J Surg Oncol. 2012; 10:4.

19. Gerratana L, Fanotto V, Bonotto M, Bolzonello S, Minisini AM, Fasola G, Puglisi F. Pattern of metastasis and outcome in patients with breast cancer. Clin Exp Metastasis. 2015; 32:125-133.

20. Lee Y, Kang E, Lee AS, Baek H, Kim EK, Park SY, Kim JH, Kim YJ, Kim SH, Kim IA, Eom KY, Kim SW. Outcomes and recurrence patterns according to breast cancer subtypes in Korean women. Breast Cancer Res Treat. 2015; 151:183-190.

21. Kennecke H, Yerushalmi R, Woods R, Cheang MC, Voduc D, Speers CH, Nielsen TO, Gelmon K. Metastatic behavior of breast cancer subtypes. J Clin Oncol. 2010; 28:3271-7.
22. Sihto H, Lundin J, Lundin M, Lehtimäki T, Ristimäki A, Holli K, Sailas L, Kataja V, Turpeenniemi-Hujanen T, Isola J, Heikkilä P, Joensuu H. Breast cancer biological subtypes and protein expression predict for the preferential distant metastasis sites: anationwide cohort study. Breast Cancer Res. 2011; 13:R87.

23. Metzger-Filho O, Sun Z, Viale G, Price KN, Crivellari D, Snyder RD, Gelber RD, Castiglione-Gertsch M, Coates AS, Goldhirsch A, Cardoso F. Patterns of recurrence and outcome according to breast cancer subtypes in lymph node-negative disease:results from international breast cancer study group trials VIII and IX. J Clin Oncol. 2013; 31:3083-3090.

24. Beca F, Santos R, Vieira D, Zeferino L, Dufloth R, Schmitt F. Primary relapse site pattern in women with triple-negative breast cancer. Pathol Res Pract. 2014; 210:571-575.

25. Lin Y, Yin W, Yan T, Zhou L, Di G, Wu J, Shen Z, Shao $\mathrm{Z}$, Lu J. Site-specific relapse pattern of the triple negative tumors in Chinese breast cancer patients. BMC Cancer. 2009; 9:342.

26. Olson EM, Najita JS, Sohl J, Arnaout A, Burstein HJ, Winer EP, Lin NU. Clinical outcomes and treatment practice patterns of patients with HER2-positive metastatic breast cancer in the post-trastuzumab era. Breast. 2013; 22:525-531.

27. Soni A, Ren Z, Hameed O, Chanda D, Morgan CJ, Siegal GP, Wei S. Breast cancer subtypes predispose the site of distant metastases. Am J Clin Pathol. 2015; 143:471-478.

28. Nielsen TO, Hsu FD, Jensen K, Cheang M, Karaca G, Hu Z, Hernandez-Boussard T, Livasy C, Cowan D, Dressler L, Akslen LA, Ragaz J, Gown AM, Gilks CB, van de Rijn M, Perou CM. Immunohistochemical and clinical characterization of the basal-like subtype of invasive breast carcinoma. Clin Cancer Res. 2004; 10:5367-5374.

29. Rakha EA, El-Sayed ME, Green AR, Lee AH, Robertson JF, Ellis IO. Prognostic markers in triple-negative breast cancer. Cancer. 2007; 109:25-32.

30. Choi YJ, Nam SJ, Son MJ, Kim DK, Kim JH, Yang JH, Kim MH, Song HS, Nam DH, Bang SI. Erlotinib prevents pulmonary metastasis in curatively resected breast carcinoma using a mouse model. Oncol Rep. 2006; 16:119-22.

31. Tham YL, Sexton K, Kramer R, Hilsenbeck S, Elledge R. Primary breast cancer phenotypes associated with propensity for central nervous system metastases. Cancer. 2006; 107:696-704.

32. Lin NU, Vanderplas A, Hughes ME, Theriault RL, Edge SB, Wong YN, Blayney DW, Niland JC, Winer EP, Weeks JC. Clinicopathologic features, patterns of recurrence, and survival among women with triple-negative breast cancer in the National Comprehensive Cancer Network. Cancer. 2012; 118:5463-5472. 
33. Li FY, Wu SG, Zhou J, Sun JY, Lin Q, Lin HX, Guan XX, He ZY. Prognostic value of Ki-67 in breast cancer patients with positive axillary lymph nodes: a retrospective cohort study. PLoS One. 2014; 9:e87264.

34. Goldhirsch A, Winer EP, Coates AS, Gelber RD, PiccartGebhart M, Thürlimann B, Senn HJ; Panel members. Personalizing the treatment of women with early breast cancer: highlights of the St Gallen International Expert
Consensus on the Primary Therapy of Early Breast Cancer 2013. Ann Oncol. 2013; 24:2206-2223.

35. Lee DS, Kim SJ, Kang JH, Hong SH, Jeon EK, Kim YK, Yoo IeR, Park JG, Jang HS, Lee HC, Kim YS. Serum Carcinoembryonic Antigen Levels and the Risk of Wholebody Metastatic Potential in Advanced Non-smallCell Lung Cancer. J Cancer. 2014; 5:663-669. 